\title{
Neutrophils in induced sputum arise from central airways
}

\author{
Y.P. Moodley, V. Krishnan, U.G. Lalloo
}

Neutrophils in induced sputum arise from central airways. Y.P. Moodley, V. Krishnan, U.G. Lalloo. (C) ERS Journals Ltd 2000.

ABSTRACT: A high neutrophil count is often found in induced sputum compared to bronchoalveolar lavage fluid (BALF). This study investigated whether such a high neutrophil count may be a response to inhaled hypertonic saline or that the airway compartment sampled by induced sputum has a higher concentration of neutrophils than BALF.

Saliva and induced sputum samples were taken at 10 and 20 min following inhalation of $3 \%$ hypertonic saline from an ultrasonic nebulizer in 12 healthy nonsmoking subjects. Four days later the 12 subjects underwent bronchoscopy (six following inhalation with $3 \%$ saline). Tracheal, proximal bronchial secretions, bronchial washings and BALF samples were obtained.

The neutrophil count (\% total leukocytes) increased significantly in saliva at 10 and 20 min post nebulization with $3 \%$ saline, although there was no change in neutrophils in induced sputum at 10 and 20 min. There was no significant difference in neutrophil count in the subjects who inhaled $3 \%$ saline as compared to those who did not, in secretions from the trachea, proximal bronchi, bronchial washings and BALF. Neutrophil counts were significantly higher in the trachea, proximal bronchi and bronchial washings as compared to BALF $(p<0.001)$.

It is concluded that neutrophil counts in healthy subjects increase from the peripheral towards the proximal airways, in the absence of hypertonic saline-induced changes. This suggests that the relatively high neutrophil count in induced sputum arises from the proximal airways and is not a response to inhaled hypertonic saline during the procedure.

Eur Respir J 2000; 15: 36-40.

The cells in induced sputum have been characterized in healthy subjects, asthmatics and in patients with chronic obstructive pulmonary diseases $[1,2]$. The technique for the collection and analysis of induced sputum is repeatable, valid [3] and responsive to changes [4] making it a useful noninvasive procedure in the investigation of lung disease.

The neutrophil count is significantly higher in induced sputum when compared to bronchoalveolar lavage fluid (BALF) in healthy subjects and asthmatics [5-7]. The reason for the neutrophilia has not been clearly elucidated and has been the subject of two recent studies $[8,9]$. The effect of sputum induction on two consecutive days resulted in a higher neutrophil count on day 2 in asthmatic and healthy subjects [8]. Repeated sputum induction in healthy volunteers showed an increase in neutrophils at 8 $\mathrm{h}$ that persisted at $24 \mathrm{~h}$ when compared to baseline [9]. The authors of the latter study suggested that this was due to a neutrophilic response to hypertonic saline inhalation in the oropharyngeal and/or subglottic airways. The high neutrophil count in induced sputum could also be the result of sampling a different compartment in the airways compared to bronchial washings and BALF.

The aim of this study therefore was to investigate the potential source of the high neutrophil count in induced sputum in healthy volunteers. It was hypothesized that the high neutrophil count in induced sputum occurs as a re- sponse in the airways to the inhalation of $3 \%$ saline, alternatively that the airway compartment sampled by induced sputum is different to that of BALF.

\section{Material and methods}

\section{Study subjects}

Nonsmoking healthy volunteers without a history of cardiorespiratory disease and absence of a viral illness in the preceding 6 weeks were recruited. They were nonatopic on skin-prick testing for common aeroallergens and had normal spirometry. All had a normal provocative concentration causing a $20 \%$ fall in forced expiratory volume in one second $(\mathrm{FEV} 1)(\mathrm{PC} 20)\left(>16 \mathrm{mg} \cdot \mathrm{mL}^{-1}\right.$ histamine $)$ to bronchial provocation testing. Sixteen subjects were recruited of which 12 subjects (six males), mean \pm SEM aged $28 \pm 2.6$ yrs produced an adequate sputum specimen (defined as at least $1 \mathrm{~mL}$ of sputum with $<50 \%$ squamous epithelial cells on differential cell counting) were studied. FEV1 was $102.4 \pm 2.9 \%$ of predicted value. The study was approved by the ethics committee of the University of Natal.

\section{Study design}

Subjects visited the laboratory on three occasions. Following a screening visit the subjects were asked to produce 
saliva at baseline, then at $10 \mathrm{~min}$ and 20 min during $3 \%$ saline inhalation. They were also requested to expectorate sputum immediately after collection of a saliva sample at 10 and 20 min during saline inhalation.

Four days later six subjects inhaled 3\% saline for $20 \mathrm{~min}$ during which sputum was collected. This was followed by a fibreoptic bronchoscopy. At bronchoscopy, tracheal and proximal (2 $\mathrm{cm}$ distal to the carina) bronchial aspirates were obtained. In addition bronchial washings and BALF were collected with the bronchoscope wedged in a segment of the right middle lobe. The remaining six subjects also had bronchoscopy with tracheal and bronchial aspirates, bronchial washings and bronchoalveolar lavage (BAL) performed without prior inhalation of $3 \%$ saline.

\section{Sputum induction}

The technique for induced sputum in this study has been described elsewhere [2]. Briefly the subjects inhaled 3\% saline from an ultrasonic nebulizer (DeVilbiss 2000; DeVilbiss Co., Heston, UK) with an output of $4.5 \mathrm{~mL} \cdot \mathrm{min}^{-1}$. The aerosol was inhaled through a tube $100 \mathrm{~cm}$ long with an internal diameter of $25 \mathrm{~mm}$ equipped with a mouthpiece and nose-clips were used.

Prior to sputum induction the subjects inhaled $200 \mu \mathrm{g}$ salbutamol from a metered dose inhaler and were then instructed to blow their noses to prevent any contamination from a post-nasal drip.

\section{Bronchoscopy and bronchoalveolar lavage fluid}

Bronchoscopy was performed using standardized procedures 4 days after sputum induction. All subjects were pretreated with $200 \mu \mathrm{g}$ salbutamol inhalation from a metered dose inhaler and then blew their noses to prevent any contamination due to post-nasal drip prior to bronchoscopy. After adequate local anaesthesia and sedation with midazolam a bronchoscope (Olympus 2000 ITD; Olympus, Tokyo, Japan) was inserted per orally.

Secretions from the trachea and $2 \mathrm{~cm}$ distal to carina were aspirated and collected separately in a mucus trap until $\sim 3 \mathrm{~mL}$ were obtained. The volumes obtained were $2.6 \pm 0.4 \mathrm{~mL}$ and $3.2 \pm 10.7 \mathrm{~mL}$, respectively. The bronchoscope was then wedged in a segmental bronchus of the right middle lobe. An aliquot of $20 \mathrm{~mL}$ of warmed normal saline was instilled and the aspirate collected. This was labelled as bronchial washing. BALF was obtained by instilling three $60 \mathrm{~mL}$ aliquots of normal saline into the segmental bronchus and gently aspirating the fluid. The returns were pooled and analysed.

\section{Processing of saliva and sputum}

Saliva and induced sputum samples were processed as described by Keatings et al. [2]. Samples were diluted with $2 \mathrm{~mL}$ Hanks balanced salt solution (HBSS) containing 1\% dithiothretol (DTT) (Sigma Chemicals, Poole, Dorset, UK) and gently vortexed at room temperature. All samples were incubated with DTT for $20 \mathrm{~min}$. When the samples appeared homogenous, the volume was recorded and centrifuged at $300 \times g$ for $10 \mathrm{~min}$. The supernatant was separated and the cell pellet resuspended in $2 \mathrm{~mL}$ HBSS. Total cell counts were determined on a haemocytometer slide using a Kimura stain and slides were made using a cytospin at $20 \times g$ for 6 min (Shandon, Runcorn, Chesire, UK) and stained with May-Grunwald Giemsa for differential cell counts, which were carried out by two blinded observers (S. Venketasamy, Dept of Haematology, University of Natal, Durban, South Africa, and Y.P. Moodley). Squamous cells were expressed as a percentage of the total cell count. Differential counts were made and expressed as a percentage of the 400 leukocytes that were counted.

Processing of bronchial washings and bronchoalveolar lavage fluid

Bronchial washings and BALF samples were transported on ice to the laboratory for processing. Bronchial washings and BALF were filtered through a nylon gauze (Sigma) and then centrifuged at $300 \times g$ for $10 \mathrm{~min}$. The pellet was resuspended in $2 \mathrm{~mL}$ HBSS and slides were prepared using a cytospin (Shandon Runcorn, UK) and stained as for induced sputum.

\section{Statistical analysis}

All results are presented as mean \pm SEM.

Observer reliability was examined by the reliability coefficient (intraclass correlation coefficient $=\mathrm{Ri}$ ) as the proportion of the variance to the true variance between observer counts [10].

The repeated measures analysis of variance (ANOVA) test was used to analyse the neutrophil counts in saliva at each time period. The repeated measures ANOVA was also used to compare the neutrophil count of BALF to other sites and to compare the neutrophil count at the different sites between the group that inhaled 3\% saline with those subjects who did not inhale $3 \%$ saline. $p<0.05$ was regarded as significant. All statistics were calculated using the SAS statistical programme. (SAS Institute, Carey, NC,USA).

\section{Results}

There was a good correlation between the two observers who performed the differential cell counts. The intraclass correlations for the different cells were: saliva squamous cells $(\mathrm{Ri}=0.8)$, saliva neutrophils $(\mathrm{Ri}=0.9)$, sputum neutrophils $(\mathrm{Ri}=0.8)$, sputum macrophages $(\mathrm{Ri}=0.8)$, sputum eosinophils $(\mathrm{Ri}=0.8)$, sputum lymphocytes $(\mathrm{Ri}=0.8)$.

\section{Saliva and induced sputum}

The results of the cells in saliva and sputum are presented in table 1 . Neutrophils comprised $0.5 \pm 0.2 \%$ of the total cells in saliva. No macrophages or lymphocytes were detected in any of the samples of saliva. There was a significant increase in neutrophils in saliva from baseline at $10 \mathrm{~min}$ and $20 \mathrm{~min}$ during inhalation with $3 \%$ saline (table 1). The neutrophils in saliva increased from $0.5 \pm$ 
Table 1. - The differential cell count in saliva and induced sputum during $3 \%$ saline inhalation

\begin{tabular}{|c|c|c|c|c|c|}
\hline & Baseline & $\begin{array}{l}\text { Saliva } \\
10 \mathrm{~min}\end{array}$ & $\begin{array}{l}\text { Induced sputum } \\
10 \mathrm{~min}\end{array}$ & $\begin{array}{l}\text { Saliva } \\
20 \mathrm{~min}\end{array}$ & $\begin{array}{l}\text { Induced sputum } \\
20 \mathrm{~min}\end{array}$ \\
\hline Total cell $^{\#}$ & $33 \pm 7.1$ & $36 \pm 8.4$ & $520 \pm 132$ & $35 \pm 10.4$ & $620 \pm 218$ \\
\hline Neutrophils & $0.5 \pm 0.2$ & $1.0 \pm 0.3$ & $18.3 \pm 4.1$ & $1.6 \pm 0.3$ & $17.6 \pm 5.1$ \\
\hline Neutrophils"\# & $0.17 \pm 0.1$ & $0.4 \pm 0.2 *$ & $90 \pm 21$ & $0.6 \pm 0.4 *$ & $109 \pm 34$ \\
\hline Macrophages & & & $74.4 \pm 6.3$ & & $75.2 \pm 8.6$ \\
\hline Squamous & $98.9 \pm 0.3$ & $97.8 \pm 0.3$ & $3.2 \pm 0.5$ & $97.8 \pm 0.3$ & $3.8 \pm 1.8$ \\
\hline Epithelial & & & $1.1 \pm 1.4$ & & $1.2 \pm 1.7$ \\
\hline Eosinophils & $0.6 \pm 0.2$ & $0.5 \pm 0.1$ & $2.5 \pm 0.4$ & $0.4 \pm 0.1$ & $2.0 \pm 0.8$ \\
\hline Lymphocytes & & & $4.3 \pm 0.4$ & & $4.8 \pm 0.7$ \\
\hline
\end{tabular}

Squamous cells are expressed as a percentage of the total cell count. Differential counts for other cell types are expressed as a percentage of airway cells excluding squamous cells. ${ }^{\#}: 10^{4}$ cells $\cdot \mathrm{mL}^{-1} .^{*}: \mathrm{p}<0.001$ (ANOVA) difference from baseline and at $10 \mathrm{~min}$ of inhalation with hypertonic saline inhalation.

$0.2 \%\left(0.2 \pm 0.1 \times 10^{4}\right.$ cells $\left.\cdot \mathrm{mL}^{-1}\right)$ at baseline to $1.0 \pm 0.3 \%$ $\left(0.4 \pm 0.3 \times 10^{4}\right.$ cells $\left.\cdot \mathrm{mL}^{-1}\right)$ at $10 \mathrm{~min}: \mathrm{p}<0.001$ and $1.6 \pm$ $0.3\left(0.6 \pm 0.3 \times 10^{4}\right.$ cells $\left.\cdot \mathrm{mL}^{-1}\right)$ at $20 \mathrm{~min}: \mathrm{p}<0.001$. Eosinophils in saliva did not change significantly from baseline at 10 and $20 \mathrm{~min}$.

There was no significant difference in the neutrophil count in induced sputum at $10 \mathrm{~min}$ and $20 \mathrm{~min} ; 18.3 \pm 4.1 \%$ $\left(90 \pm 21 \times 10^{4}\right.$ cells $\left.\cdot \mathrm{mL}^{-1}\right)$ and $17.6 \pm 5.1 \%\left(109 \pm 34 \times 10^{4}\right.$ cells $\cdot \mathrm{mL}^{-1}$ ) respectively: $\mathrm{p}>0.5$.

\section{Bronchoscopy}

The total and differential cell counts from the sites sampled at bronchoscopy were similar in subjects who did and did not inhale 3\% saline. The data for subjects who did not inhale $3 \%$ saline is presented in table 2 and figure 1 . The neutrophils were significantly higher in the trachea (16.7 \pm $5.7 \%)$ and proximal bronchi $(18.8 \pm 4.2 \%)$ as compared to BALF $(2.0 \pm 0.4 \%): p<0.001$ in subjects who inhaled $3 \%$ saline prior to bronchoscopy and were not significantly different to those for subjects who did not inhale $3 \%$ saline. There was a significantly higher concentration of neutrophils in bronchial washings $(6.7 \pm 2.1 \%)$ compared to BALF $(1.8 \pm 0.7 \%) ; \mathrm{p}<0.001$ (table 3 ).

The concentration of epithelial cells fell progressively from the proximal to distal compartments (table 2). The concentration of epithelial cells was higher in the trachea $(\mathrm{p}<0.001)$ and proximal bronchi $(\mathrm{p}<0.001)$ in comparison to induced sputum. There was no significant difference

Table 2. - Differential cell counts in tracheal, tracheobronchial and bronchial washings and bronchoalveolar lavage fluid (BALF) (without 3\% hypertonic saline inhalation)

\begin{tabular}{lcccc}
\hline & Trachea & $\begin{array}{c}\text { Proximal- } \\
\text { bronchial }\end{array}$ & $\begin{array}{c}\text { Bronchial } \\
\text { washing }\end{array}$ & BALF \\
\hline Cell count & $1.3 \pm 0.1$ & $1.2 \pm 0.1$ & $3.5 \pm 0.1$ & $7.0 \pm 1.5$ \\
Epithelial & $4.9 \pm 0.6^{*}$ & $4.4 \pm 0.7^{*}$ & $1.1 \pm 0.4^{*}$ & - \\
Neutrophils & $16.9 \pm 4.2^{*}$ & $17.3 \pm 3.7^{*}$ & $6.7 \pm 2.1^{*}$ & $1.8 \pm 0.7$ \\
Eosinophils & $1.2 \pm 0.3$ & $1.8 \pm 0.4$ & $1.9 \pm 0.3$ & $2.0 \pm 0.7$ \\
Macrophages & $62.3 \pm 0.9^{*}$ & $71.0 \pm 1.3^{*}$ & $81.9 \pm 1.1$ & $89.5 \pm 3.8$ \\
Lymphocytes & $5.5 \pm 1.2$ & $5.7 \pm 1.2$ & $9.50 \pm 0.9^{*}$ & $6.7 \pm 0.7$ \\
\hline
\end{tabular}

Data are expressed as mean \pm SEM. Cell count is expressed as $\times 10^{6}$ cells $\cdot \mathrm{mL}^{-1}$, while all other cell types are expressed as percentages of the cell count. *: $\mathrm{p}<0.001$ (ANOVA) comparing proximal secretions to BALF. between lymphocyte concentrations ( $p>0.6)$ as well as eosinophil concentrations ( $p>0.7)$ in BALF when compared to tracheal secretions.

Table 3 shows that the neutrophil percentage in the trachea, proximal bronchi and bronchial washings in subjects who inhaled $3 \%$ saline did not differ significantly from those who did not.

\section{Discussion}

This study demonstrated a significant increase in neutrophils in saliva during hypertonic saline inhalation. This did not directly influence the neutrophil count in induced sputum because the absolute number of neutrophils in saliva was small. This study confirmed that neutrophils were in a significantly higher concentration in secretions sampled from the proximal airways and steadily decreased down the tracheobronchial tree. Prior inhalation of hypertonic saline did not increase the number of neutrophils in secretions from the trachea, proximal bronchus, subsegmental bronchus and BALF. Thus it is suggested that the increased neutrophils found in induced sputum in comparison to BALF is due to the contribution from the proximal airways, not sampled during collection of BALF.

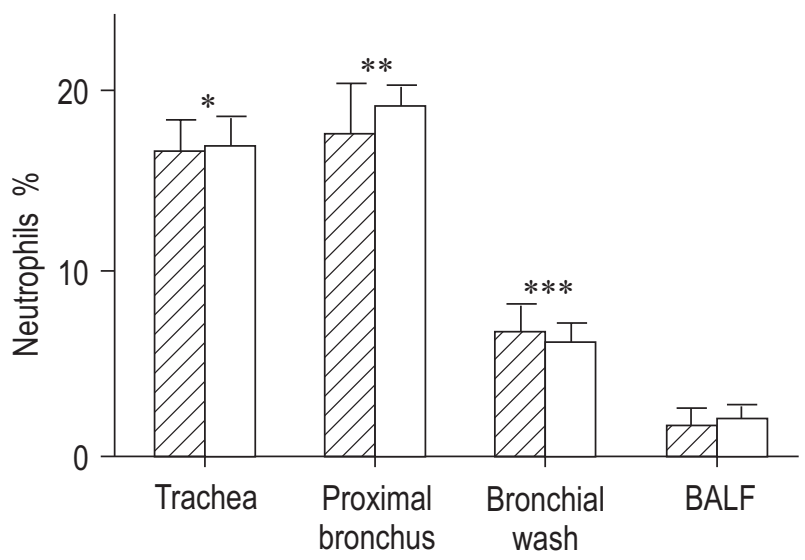

Fig. 1. - The proportion of neutrophils in secretions obtained from different sites in the tracheobronchial tree and bronchoalveolar lavage fluid (BALF) showing the difference between samples obtained with $(\square)$ and without $(\mathbb{Z}) 3 \%$ saline inhalation at each site. ${ }^{*}: \mathrm{p}<0.001$ for trachea compared to BALF; $* *$ : $p<0.001$ for proximal bronchus compared to BALF; ***: $\mathrm{p}<0.001$ for bronchial washing compared to BALF. 
Table 3. - Neutrophil count (percentage of leukocytes) in airway secretions obtained at bronchoscopy with and without inhalation of $3 \%$ hypertonic saline

\begin{tabular}{lcccc}
\hline & Trachea & $\begin{array}{c}\text { Proximal- } \\
\text { bronchial }\end{array}$ & $\begin{array}{c}\text { Bronchial } \\
\text { washing }\end{array}$ & BALF \\
\hline $\begin{array}{l}\text { Without 3\% } \\
\text { saline inhalation }\end{array}$ & $16.4 \pm 4.2$ & $17.3 \pm 3.7$ & $6.7 \pm 2.1$ & $1.8 \pm 0.7$ \\
$\begin{array}{l}\text { With 3\% saline } \\
\text { inhalation }\end{array}$ & $16.7 \pm 5.7$ & $18.8 \pm 4.2$ & $6.2 \pm 3.3$ & $2.0 \pm 0.4$ \\
ANOVA & $\mathrm{p}>0.4$ & $\mathrm{p}>0.4$ & $\mathrm{p}>0.5$ & $\mathrm{p}>0.6$ \\
\hline
\end{tabular}

Data are presented as mean \pm SEM. BALF: bronchoalveolar lavage fluid.

The increased neutrophil count in saliva during inhalation of hypertonic saline found in this study has been observed previously [3]. A recent study demonstrated no difference in the neutrophil count in samples of sputum plugs separated from saliva compared to samples of sputum that included saliva, supporting the current findings that the neutrophil count in saliva did not influence the neutrophil count in sputum [10]. It is postulated that the accumulation of hypertonic saline in the oropharynx may cause an ingress of neutrophils into this compartment. The mechanism of this is unclear.

The effect of inhalation of hypertonic saline on neutrophil counts in induced sputum has been addressed in two studies involving healthy subjects. Holz et al. [8] demonstrated a significant increase in neutrophils in induced sputum $24 \mathrm{~h}$ after a prior sputum induction. They also demonstrated that the neutrophils progressively decreased in induced sputum with inhalation of increasing concentrations of hypertonic saline $(3 \%, 4 \%$ and $5 \%)$ at three 10 min periods. The present study used the same concentration of hypertonic saline $(3 \%)$ during two consecutive sputum inductions at $10 \mathrm{~min}$ intervals and found no statistically significant difference in neutrophil numbers. The authors cannot explain the differences except to acknowledge the use of the increasing concentration of hypertonic saline in the study by Holz et al. [8] and that the time lag between the repeat sputum induction was not specified. Nightingale et al. [9] demonstrated a significant increase in the percentage of neutrophils with repeated hypertonic saline inhalation at $8 \mathrm{~h}$ and $24 \mathrm{~h}$ after the initial sputum induction, but there was no statistically significant increase in the absolute neutrophil count. It appears from the current study that hypertonic saline inhalation does not increase the neutrophils in induced sputum over a short period of time. This is supported by the observation that neutrophil numbers were similar in spontaneously produced sputum and induced sputum [11].

The present study also demonstrated that the neutrophils in the trachea, proximal airways, and segmental bronchi were significantly increased when compared with bronchial washings and BALF. This observation is consistent with findings of other studies demonstrating a higher neutrophil count in bronchial washings compared to BALF [5, 12]. A study that investigated BALF in asthma showed that the neutrophil count in aspirated bronchial mucus during bronchoscopy also had a higher neutrophil count compared to BALF [13]. It is therefore speculated that the high neutrophil count in induced sputum in asthmat$25 \%$ in the intra-epithelial layer, possibly explaining the source of neutrophils in the proximal airway secretions noted in the current study [14]. The high neutrophil count in the trachea and proximal bronchi with a decreasing count in the more distal bronchi may contribute significantly to the neutrophil count in induced sputum. The mucociliary escalator may also serve to concentrate neutrophils in the tracheal and proximal bronchial secretions. Nebulized hypertonic saline has been shown to increase mucociliary clearance [15]. Post-nasal drip is another possibility for the neutrophil predominance in the trachea and proximal bronchi although the precaution was taken to minimize contamination from this source by ensuring the subjects blew their noses prior to the procedure and only healthy nonatopic subjects were selected.

A possible explanation for the lack of an influence of hypertonic saline on induced sputum may be that the sample number $(n=6)$ was too small to detect a difference. Firstly, there was sufficient statistical power to detect a difference, if any, in neutrophil numbers in saliva following hypertonic saline inhalation and between the proximal airways and BALF. The study had the power to detect a $>4 \%$ difference in neutrophil numbers at the trachea and proximal bronchus with and without hypertonic saline inhalation. The authors think that a difference smaller than this would not influence the neutrophil count in induced sputum. The observation by Pizzichini et al. [16] that there was no difference in neutrophil numbers spontaneously produced and induced sputum further supports the conclusion that hypertonic saline does not increase the neutrophils in induced sputum. The study by Holz et al. [8] showed that repeated hypertonic saline inhalation, in fact, reduces the neutrophil count in the short term.

There were a high number of lymphocytes and eosinophils in the current study compared to several other studies on induced sputum in healthy subjects $[3,17,18]$. The lymphocyte count in this study is in keeping with other studies in normal subjects $[8,9]$. The eosinophil count in induced sputum in the current study was similar to that found by PIN et al. [19]. The BALF eosinophil count is also elevated in this study [20]. None of the subjects in the current study were atopic and none had bronchial hyperreactivity and the high eosinophil count is thus unexplained. Two studies $[3,18]$ used a lower concentration of DTT for the processing of induced sputum. The yield of cells may be influenced by different concentrations of DTT and exposure to DTT for longer periods in the processing of sputum samples [21]. Different cytocentrifuge and cytospin speeds may result in differences in cell counts in BALF [20] and this may also be true for induced sputum. KIPS et al. [22] suggest that differences in processing between laboratories are not significant, provided the processing within laboratories is consistent. The differential cell counts in induced sputum and BALF in this study are repeatable and consistent with the normal values of healthy subjects in other studies undertaken at the current authors' laboratory.

It is therefore concluded that the high neutrophil count in induced sputum compared to bronchoalveolar lavage fluid is most likely a contribution from the high neutrophil numbers in the trachea and proximal airways. Although a local response to nebulized hypertonic saline did occur at the oropharyngeal level the increase was too small to directly influence the neutrophil concentration in induced sputum. 
Acknowledgements. The authors would like to thank C. Connelly from the Institute of Biostatistics of the Medical Research Council for assistance with the statistical analysis.

\section{References}

1. Iredale MJ, Wanklyn AR, Phillips IP, Krausz T, Ind PW. Non-invasive assessment of bronchial inflammation in asthma: no correlation between eosinophilia of induced sputum and bronchial responsiveness to inhaled hypertonic saline. Clin Exp Allergy 1994; 24: 940-945.

2. Keatings VM, Collins PD, Scott DM, Barnes PJ. Differences in interleukin- 8 and tumor necrosis factor- $\alpha$ in induced sputum from patients with chronic obstructive pulmonary disease or asthma. Am J Respir Crit Care Med 1996; 153: 530-534.

3. Pizzichini E, Pizzichini MM, Ethimiadis A. Indices of airway inflammation in induced sputum: reproducibility and validity of cell and fluid-phase measurements. Am J Respir Crit Care Med 1996; 154: 308-317.

4. Fahy JV, Liu J, Wong H, Boushey HA. Analysis of cellular and biochemical constituents in induced sputum after allergen challenges: a method for studying allergic airway inflammation. J Allergy Clin Immunol 1994; 93: 1031-1039.

5. Keatings VM, Evans DJ, O'Connor BJ, Barnes PJ. Cellular profile in asthmatic airways: a comparison of induced sputum, bronchial washings and bronchoalveolar lavage fluid. Thorax 1997; 52: 372-374.

6. Maestrelli P, Saetta M, Di Stefano A, et al. Comparison of leukocyte counts in sputum, bronchial biopsies and bronchoalveolar lavage. Am J Respir Crit Care Med 1995; 152: 1926-1931.

7. Grootendorst DC, Sont JK, Willems LNA, et al. Comparison of inflammatory cell counts in asthma: induced sputum versus bronchoalveolar lavage and bronchial biopsies. Clin Exp Allergy 1997; 27: 769-779.

8. Holz O, Richter K, Jorres RA, Speckin P, Mucke M, Magnussen $\mathrm{H}$. Changes in sputum composition between two inductions performed on consecutive days. Thorax 1998; 53: 83-86.

9. Nightingale JA, Rogers DF, Barnes PJ. Effect of repeated sputum induction on cell counts in normal volunteers. Thorax 1998; 53: 87-90.

10. Bland JM, Altman DG. Statistical methods for assessing agreement between two methods of clinical measurement Lancet 1986; i: 307-310.
11. Pizzichini MMM, Popov TA, Efthmiadis A, et al. Spontaneous and induced sputum to measure indices of airway inflammation in asthma. Am Rev Respir Dis 1996; 154: 866-869.

12. Rennard SI, Ghafouri MO, Thompson AB, et al. Fractional processing of sequential bronchoalveolar lavage to separate bronchial and alveolar samples. Am Rev Respir Dis 1990; 141: 208-217.

13. Diaz P, Galleguillos FR, Gonzalez MC, Pantin CFA, Kay AB. Bronchoalveolar lavage in asthma: the effect of disodium cromoglycate (cromolyn) on leukocyte counts, immunoglobulins and complement. J Allergy Clin Immunol 1984; 74: 41-48.

14. Jeffery PK, Wardlaw J, Nelson FC, Collins JV, Kay AB. Bronchial biopsies in asthma: an ultrastructural, quantitative study and correlation with hyperreactivity. Am Rev Respir Dis 1989; 140: 1745-1753.

15. Daviskas E, Anderson SD, Gonda I, et al. Inhalation of hypertonic saline aerosol enhances mucocilliary clearance in asthmatic and healthy subjects. Eur Respir J 1996; 9: 725-732.

16. Pizzichini E, Pizzichini MM, Efthimiadis A, Hargreave FE, Dolovich J. Measurement of inflammatory indices in induced sputum: effects of selection of sputum to minimize salivary contamination. Eur Respir J 1996; 9: 11741180.

17. Gershman NH, Wong HH, Liu JT, Mahlmeister MJ, Fahy JV. Comparison of two methods of collecting induced sputum in asthmatic subjects. Eur Respir $J$ 1996; 9: $2448-2453$.

18. In't Veen JCCM, de Gouw HWFM, Smits HH, et al. Repeatability of cellular and soluble markers of inflammation in induced sputum from patients with asthma. Eur Respir J 1996; 9: 2441-2447.

19. Pin J, Gibson PG, Kolendowicz R, et al. Use of induced sputum cell counts to investigate airway inflammation in asthma. Thorax 1992; 47: 25-29.

20. Saltini C, Hance AJ, Ferrans VJ, Basset F, Bitterman PB, Crystal RG. Accurate quantification of cells recovered by bronchoalveolar lavage. Am Rev Respir Dis 1984; 130: 650-658.

21. Popov T, Gottschalk R, Kolendowicz R, Dolovich J, Powers P, Hargreave FE. The evaluation of a cell dispersion method of sputum examination. Clin Exp Allergy 1994; 24: 778-783.

22. Kips JC, Peleman RA, Pauwels RA. Methods of examining induced sputum: do differences matter? Eur Respir $J$ 1998; 11: 529-533. 